\title{
Impact of functional mandibular advancement appliances on the temporomandibular joint - a systematic review
}

\author{
Laura Ivorra-Carbonell ${ }^{1}$, José-María Montiel-Company ${ }^{2}$, José-Manuel Almerich-Silla ${ }^{3}$, Vanessa Paredes- \\ Gallardo $^{2}$, Carlos Bellot-Arcís ${ }^{4}$
}

\footnotetext{
${ }^{1}$ Dentistry graduate, Stomatology Department, Faculty of Medicine and Dentistry, University of Valencia, Spain

${ }^{2}$ Teaching Assistant, Stomatology Department, Faculty of Medicine and Dentistry, University of Valencia, Spain

${ }^{3}$ Tenured Lecturer, Stomatology Department, Faculty of Medicine and Dentistry, University of Valencia, Spain

${ }^{4}$ Associate Lecturer, Stomatology Department, Faculty of Medicine and Dentistry, University of Valencia, Spain
}

Correspondence:

Departamento de Estomatología

Unidad Docente de Ortodoncia

Clínica Odontológica

C/ Gascó Oliag $n^{\circ} 1$

46010, Valencia, Spain

bellot.arcis@gmail.com

Received: $02 / 12 / 2015$

Accepted: 28/02/2016

\author{
Ivorra-Carbonell L, Montiel-Company JM, Almerich-Silla JM, Paredes- \\ Gallardo V, Bellot-Arcís C. Impact of functional mandibular advance- \\ ment appliances on the temporomandibular joint - a systematic review. \\ Med Oral Patol Oral Cir Bucal. 2016 Sep 1;21 (5):e565-72. \\ http://www.medicinaoral.com/medoralfree 01/v21i5/medoralv21i5p565.pdf \\ Article Number: $21180 \quad$ http://www medicinaoral.com/ \\ (C) Medicina Oral S. L. C.I.F. B 96689336 - pISSN 1698-4447 - eISSN: 1698-6946 \\ eMail: medicina@medicinaoral.com \\ Indexed in: \\ Science Citation Index Expanded \\ Journal Citation Reports \\ Index Medicus, MEDLINE, PubMed \\ Scopus, Embase and Emcare \\ Indice Médico Español
}

\begin{abstract}
Background: Although many orthodontists have no doubts about the effectiveness of functional appliances for mandibular advancement, the impact on the temporomandibular joint (TMJ) is still in dispute. The objective of this systematic review is to examine the main effects on the TMJ of using functional appliances, both in healthy patients and in patients with a pre-existing disorder.

Material and Methods: A systematic review of the literature was conducted in accordance with the PRISMA guidelines. Only systematic reviews, meta-analyses, randomized clinical trials (RCTs), case-control studies and cohort studies were included. A detailed language-independent electronic search was conducted in the Pubmed, Scopus, Cochrane Library and Embase databases. All studies published between 2000 and 2015 were included.

Results: A total of 401 articles were identified. Of these, 159 were duplicates and were excluded. On reading the title and abstract, 213 articles were excluded because they did not answer the research question, leaving a total of 29 articles. These articles were read and assessed. Following critical reading of the full text, eight articles were excluded: seven because they were considered of low quality and one because it published redundant data. As a result, 21 articles were included.

Conclusions: After treatment with functional appliances, the condyle was found to be in a more advanced position, with remodelling of the condyle and adaptation of the morphology of the glenoid fossa. No significant adverse effects on the TMJ were observed in healthy patients and the appliances could improve joints that initially presented forward dislocation of the disk.
\end{abstract}

Key words: Temporomandibular joint, TMJ, orthodontic appliances, functional, mandibular advancement, herbst appliance, bionator. 


\section{Introduction}

The use of a mandibular advancement appliance to correct skeletal malocclusions associated with mandibular retrognathism is indicated during the first stage of orthodontic treatment (1). The objective is to stimulate mandibular growth and correct the sagittal misalignment by bringing the condyles forward and downward within the glenoid fossa $(2,3)$, as well as remodelling the condyle and glenoid fossa, causing anterior rotation of the mandible and consequently projecting it forwards (4). During this first stage, mandibular retrognathism can be treated with either fixed or removable functional appliances $(3,5)$. The treatment period lasts approximately 6 to 9 months (4).

When the functional appliance is inserted, the condyles are moved to a higher position in the articular eminence, which is capable of adaptation, so it could be hypothesized that some morphological changes may take place (6).

Although many orthodontists have no doubts about the effectiveness of functional appliances, their impact on the TMJ is still considered a subject of debate. It is therefore of clinical and scientific interest to investigate the most relevant effects of different functional appliances on the TMJ, particularly with current diagnostic methods. Many authors assert that treatment with these devices does not increase the prevalence of temporomandibular disorders (1,7-9). Another important aspect is the positive or negative effect that functional appliances may have on the TMJ of patients with a pre-existing disorder (1).

The main objective of this systematic review is to examine the main effects on the TMJ of different functional appliances for mandibular advancement, both in healthy patients and in patients with a pre-existing disorder.

\section{Material and Methods}

A systematic review of the bibliography was carried out in accordance with the PRISMA (Preferred Reporting Items for Systematic Reviews and Meta-Analyses) recommendations (10) and CONSORT criteria (11).

- Eligibility criteria

The selection criteria for inclusion in the review were: articles, articles in press and reviews. Only the following types of study were accepted: systematic reviews, metaanalyses, randomized clinical trials (RCTs), case-control studies and cohort studies. Both retrospective and prospective studies were included. The articles that met these criteria and studied changes in the temporomandibular joint following the use of functional appliances for mandibular advancement were included in the review.

- Search strategy and screening

To identify the relevant studies, irrespective of language, a thorough electronic search was conducted in the Pubmed, Scopus, Cochrane Library and Embase da- tabases. All studies published between 2000 and 2015 were included. The search was updated on 4 July 2015. The search strategy was implemented through a combination of the following $6 \mathrm{MeSH}$ terms: "Temporomandibular joint", "TMJ", "Functional orthodontic appliances", "Mandibular advancement", "Herbst appliance", "Bionator" and "Activator appliances", and others: "Fränkel Function Regulator", "Orthodontic Appliances", "Activator", "Function Activator", "Bionator Appliance", "Functional Orthodontic" and "Twin Block". The TMJ related terms were combined using the OR Boolean operator, as well as those related to the mandibular advancement devices. Both groups were combined using the AND Boolean operator. Hand-searching in the reference lists of the articles assessed for the review was also carried out.

Two independent reviewers assessed the titles and abstracts of all the articles selected. In the event of their disagreeing, a third reviewer was consulted. If the abstract did not provide sufficient information for a decision, the reviewers read the full article before taking the final decision. The reviewers then read the full text of all the resulting articles.

\section{- Data extraction}

For each article assessed, the following variables were recorded: author, year published, type of study (retrospective, prospective, controlled, not controlled), sample size, dropouts, demographic variables (gender, age), type of appliance used, type of advancement (sequential or otherwise), presence or otherwise of pre-existing TMJ disorders, length of treatment, type of radiographic study used to study the changes, follow-up time for each study and quality of the articles accepted (Table 1). The articles were classified as being of high, medium or low quality according to the CONSORT criteria (11) adapted by Mattos et al. (12) and used by FernándezFerrer et al. and Serra-Torres et al. $(13,14)$. The quality of the systematic reviews was assessed in accordance with the PRISMA guidelines (10).

\section{Results}

A thorough search identified 201 articles in Medline, 168 in Scopus, none in the Cochrane Library and 32 in Embase, making a total of 401 articles. 159 duplicates were removed, leaving 242 . After reading the title and abstract, 213 were removed because they did not answer the research question, leaving a total of 29 articles. These were read and carefully assessed. Detailed critical reading of the full text resulted in the exclusion of 8 articles, 7 because of their low quality (Fig. 1) and 1 because it published redundant data. Consequently, 21 articles that met all the inclusion criteria and were of medium to high quality were included in the review. It should be mentioned that the manual search did not identify any relevant articles. 
Table 1. Articles included, with information from each.

\begin{tabular}{|c|c|c|c|c|c|c|c|c|c|c|}
\hline Author/year & TS & $\begin{array}{c}\text { N (dropouts) } \\
\text { Gender (W/M) }\end{array}$ & $\begin{array}{c}\text { Age } \\
\text { (years) }\end{array}$ & $\begin{array}{c}\begin{array}{c}\text { Pre- } \\
\text { existing }\end{array} \\
\text { disorder } \\
\text { (Yes/No) }\end{array}$ & $\begin{array}{l}\text { Functional } \\
\text { advance_ } \\
\text { ment } \\
\text { appliance } \\
\end{array}$ & $\begin{array}{l}\text { Advance_- } \\
\text { ment type }\end{array}$ & $\begin{array}{c}\text { Length of } \\
\text { use } \\
\text { (months) }\end{array}$ & $\begin{array}{l}\text { X-ray } \\
\text { study }\end{array}$ & $\begin{array}{l}\text { Assessments } \\
\text { during } \\
\text { follow-up }\end{array}$ & Q \\
\hline $\begin{array}{l}\text { Chintakanon } \\
\text { et al. } 2000 \text { (19) }\end{array}$ & $\mathrm{PC}$ & $\begin{array}{c}40(0) \\
13 \mathrm{~W}, 27 \mathrm{M} \\
\mathrm{TG}=19, \mathrm{CG}=21\end{array}$ & $11.6 \pm 1.3$ & - & TW & - & 6 & $\begin{array}{l}\text { MR } \\
\text { CTr }\end{array}$ & $\begin{array}{l}\text { T0 } \\
\text { T3: } 6 \mathrm{~m}\end{array}$ & M \\
\hline $\begin{array}{l}\text { Arat et al. } 2001 \\
\text { (25) }\end{array}$ & $\mathrm{PC}$ & $\begin{array}{c}18(0) \\
12 \mathrm{~W}, 6 \mathrm{M} \\
\mathrm{TG}=9, \mathrm{CG}=9\end{array}$ & 10.5 & No & $\mathrm{AC}$ & - & 6 & $\begin{array}{l}\text { MR } \\
\text { CTr } \\
\text { WX }\end{array}$ & $\begin{array}{l}\text { T1 } \\
\text { T3: } 6 \mathrm{~m}\end{array}$ & M \\
\hline $\begin{array}{l}\text { Watted et al. } \\
2001(27)\end{array}$ & $\mathrm{PNC}$ & $\begin{array}{c}15(0) \\
7 \mathrm{M}, 8 \mathrm{~W}\end{array}$ & $11.6 \pm 0.6$ & - & BPE & - & 12 & MR & $\begin{array}{l}\text { T0 } \\
\text { T3: } 12 \mathrm{~m}\end{array}$ & M \\
\hline $\begin{array}{l}\text { Baltromejus } \\
\text { et al. } 2002 \text { (5) }\end{array}$ & PNC & $\begin{array}{c}138(0) \\
76 \mathrm{M}, 62 \mathrm{~W} \\
\mathrm{AC}=40, \mathrm{H}=98\end{array}$ & 11.5 & - & $\begin{array}{c}\mathrm{AC} \\
\mathrm{H}\end{array}$ & - & $\begin{aligned} \mathrm{AC} & =31.2 \\
\mathrm{H} & =7.2\end{aligned}$ & $\mathrm{CTr}$ & $\begin{array}{l}\mathrm{T} 2= \\
\mathrm{AC}=2 \mathrm{y}, 7 \mathrm{~m} \\
\mathrm{H}=7 \mathrm{~m}\end{array}$ & M \\
\hline $\begin{array}{l}\text { Franco et al. } \\
2002(17)\end{array}$ & $\mathrm{PC}$ & $\begin{array}{c}56(0) \\
29 \mathrm{M}, 27 \mathrm{~W} \\
\mathrm{TG}=28, \mathrm{CG}=28\end{array}$ & 8.9 to 12.5 & Yes & $\mathrm{F}$ & 1S & 18 & MR & $\begin{array}{l}\text { T0 } \\
\text { T3: } 18 \mathrm{~m}\end{array}$ & M \\
\hline $\begin{array}{l}\text { Güner } \text { et al. } \\
2003(2)\end{array}$ & $\mathrm{PC}$ & $\begin{array}{c}17(0) \\
9 \mathrm{M}, 8 \mathrm{~W} \\
\mathrm{TG}=10, \mathrm{CG}=7\end{array}$ & 13.9 & - & MARS & - & 10 & SPECT & $\begin{array}{l}\text { T0 } \\
\text { T3: } 10 \mathrm{~m}\end{array}$ & M \\
\hline $\begin{array}{l}\text { Katsavrias et al. } \\
2003 \text { (6) }\end{array}$ & PNC & $\begin{array}{c}35(0) \\
18 \mathrm{M}, 17 \mathrm{~W}\end{array}$ & 8 to 15.1 & - & $\mathrm{AC}$ & - & 16 & $\mathrm{CTr}$ & $\begin{array}{l}\text { T0 } \\
\text { T3: } 15.96 \mathrm{~m}\end{array}$ & M \\
\hline $\begin{array}{l}\text { Pancherz et al. } \\
2003(21)\end{array}$ & $\mathrm{PC}$ & $\begin{array}{c}118(83) \\
23 \mathrm{M}, 12 \mathrm{~W} \\
\mathrm{TG}=23, \mathrm{CG}=12\end{array}$ & 13.7 & - & $\mathrm{H}$ & - & 7.5 & $\mathrm{CTr}$ & $\begin{array}{l}\text { T0 } \\
\text { T3: } 7.5 \mathrm{~m} \\
\text { T4: } 2-4 \mathrm{y}\end{array}$ & M \\
\hline $\begin{array}{l}\text { Pancherz et al. } \\
2004 \text { (22) }\end{array}$ & PNC & $\begin{array}{c}118(50) \\
42 \mathrm{M}, 26 \mathrm{~W}\end{array}$ & 12.4 & - & $\mathrm{H}$ & - & 7 & $\mathrm{CTr}$ & $\begin{array}{l}\text { T0 } \\
\text { T3: } 7 \mathrm{~m} \\
\text { T4: } 4 / 6 \mathrm{y} \\
\end{array}$ & M \\
\hline $\begin{array}{l}\text { Kinzinger et al. } \\
2006(28)\end{array}$ & PNC & $\begin{array}{c}15(0) \\
8 \mathrm{M}, 7 \mathrm{~W}\end{array}$ & 15.5 & Yes & FAA & - & 7.5 & $\begin{array}{l}\mathrm{MR} \\
\mathrm{ME}\end{array}$ & $\begin{array}{l}\text { T0. T1. T2 } \\
\text { T3: } 7.5 \mathrm{~m}\end{array}$ & M \\
\hline $\begin{array}{l}\text { Kinzinger et al. } \\
2006 \text { (7) }\end{array}$ & PNC & $\begin{array}{c}20(0) \\
11 \mathrm{M}, 9 \mathrm{~W}\end{array}$ & 16 & - & FAA & - & 7.3 & MR & $\begin{array}{l}\text { T0. T1 } \\
\text { T2: } 3.65 \mathrm{~m} \\
\text { T3: } 7.3 \mathrm{~m}\end{array}$ & M \\
\hline $\begin{array}{l}\text { Kinzinger et al. } \\
2006(8)\end{array}$ & PNC & $\begin{array}{c}20(0) \\
11 \mathrm{M}, 9 \mathrm{~W}\end{array}$ & 16 & Yes & $\begin{array}{c}\text { FAA } \\
\mathrm{H}\end{array}$ & - & 7.3 & MR & $\begin{array}{l}\text { T0. T1 } \\
\text { T2: } 3.65 \mathrm{~m} \\
\text { T3: } 7.3 \mathrm{~m}\end{array}$ & M \\
\hline $\begin{array}{l}\text { Ruf et al. } \\
2007 \text { (26) }\end{array}$ & $\mathrm{PNC}$ & $\begin{array}{c}40(4) \\
20 \mathrm{M}, 20 \mathrm{~W}\end{array}$ & $11.9 \pm 1.3$ & - & $\begin{array}{l}\mathrm{VB} \\
\mathrm{AC}\end{array}$ & - & 2 & $\mathrm{CTr}$ & $\begin{array}{l}\text { T0: } 6 \mathrm{~m} \\
\text { before Tx } \\
\text { T1 } \\
\text { T4: } 12 \mathrm{~m}\end{array}$ & M \\
\hline $\begin{array}{l}\text { Kinzinger et al. } \\
2007(20)\end{array}$ & PNC & $\begin{array}{c}20(0) \\
10 \mathrm{M}, 10 \mathrm{~W}\end{array}$ & 15.5 & - & FAA & - & 7.2 & MR & $\begin{array}{l}\text { T0. T1 } \\
\text { T2: } 3.3 \mathrm{~m} \\
\text { T3: } 7.2 \mathrm{~m}\end{array}$ & M \\
\hline $\begin{array}{l}\text { Serbesis- } \\
\text { Tsarudis et al. } \\
2008 \text { (4) }\end{array}$ & $\mathrm{PC}$ & $\begin{array}{c}64(0) \\
29 \mathrm{M}, 35 \mathrm{~W} \\
\mathrm{TG}=40, \mathrm{CG}=24\end{array}$ & $12.3 \pm 1.3$ & - & $\mathrm{H}$ & - & 7 & $\mathrm{CTr}$ & $\begin{array}{l}\text { T0. T3: } 7 \mathrm{~m} \\
\text { T4: } 31 \mathrm{~m}\end{array}$ & A \\
\hline $\begin{array}{l}\text { Wadhawan } \\
\text { et al. } 2008(15)\end{array}$ & $\mathrm{PNC}$ & $\begin{array}{c}14(2) \\
4 \mathrm{M}, 10 \mathrm{~W}\end{array}$ & $10-14$ & No & $\begin{array}{c}\text { TW } \\
\text { B }\end{array}$ & - & 6 & MR & $\begin{array}{l}\text { T0. T3: } 6 \mathrm{~m} \\
\text { T4 }\end{array}$ & M \\
\hline $\begin{array}{l}\text { Aidar et al. } \\
2010 \text { (1) }\end{array}$ & PNC & $\begin{array}{c}32(9) \\
16 \mathrm{M}, 16 \mathrm{~W}\end{array}$ & $12.9 \pm 1.2$ & Yes & $\mathrm{H} \mathrm{M}$ & Seq & $38.4 \pm 1$ & MR & $\begin{array}{l}\text { T1. T2 } \\
\text { T3: } 12 \mathrm{~m} \\
\text { T4 } \\
\end{array}$ & M \\
\hline $\begin{array}{l}\text { Le Cornu et al. } \\
2013 \text { (3) }\end{array}$ & $\mathrm{PC}$ & $\begin{array}{c}14(0) \\
\mathrm{CG}=7, \mathrm{TG}=7\end{array}$ & 13.2 & No & $\mathrm{H}$ & Seq & $11.4 \pm 1$ & $\mathrm{CBCT}$ & $\begin{array}{l}\text { T0 } \\
\text { T3: } 11.42 \pm \\
1.4 \mathrm{~m}\end{array}$ & M \\
\hline $\begin{array}{l}\text { Chavan et al. } \\
2014 \text { (16) }\end{array}$ & $\mathrm{PC}$ & $\begin{array}{c}30(0) \\
17 \mathrm{M}, 13 \mathrm{~W} \\
\mathrm{TG}=20, \mathrm{CG}=10\end{array}$ & $9-14$ & - & $\begin{array}{c}\text { TW } \\
\text { B }\end{array}$ & - & 6 & MR & $\begin{array}{l}\text { T0 } \\
\text { T3: } 6 \mathrm{~m}\end{array}$ & M \\
\hline $\begin{array}{l}\text { Yildirim et al. } \\
2014 \text { (23) }\end{array}$ & $\mathrm{RNC}$ & $\begin{array}{c}30(0) \\
16 \mathrm{M}, 14 \mathrm{~W}\end{array}$ & 12.7 & - & TW & - & 7.4 & $\mathrm{CBCT}$ & $\begin{array}{l}\text { T0 } \\
\text { T3: } 7.4 \mathrm{~m}\end{array}$ & M \\
\hline
\end{tabular}

$\mathrm{TS}=$ type of study, $\mathrm{R} / \mathrm{P}=$ retrospective/prospective, $\mathrm{C} / \mathrm{NC}=$ controlled $/$ not controlled; $\mathrm{N}=$ sample size, $\mathrm{M} / \mathrm{W}=$ men $/$ women, $\mathrm{TG}=$ treatment group, $\mathrm{CG}=$ control group; $\mathrm{TA}=$ type of advancement, $\mathrm{S}$ = one-step, $\mathrm{Seq}=$ sequential; $\mathrm{FA}=$ functional appliance, $\mathrm{AC}=$ Activator, $\mathrm{B}=$ Bionator, $\mathrm{BPE}=$ Bionator plus extraoral, $\mathrm{F}=$ Fränkel, $\mathrm{FAA}=$ functional advancement appliance, $\mathrm{FFA}=$ functional fixed appliance, $\mathrm{H}=$ Herbst, $\mathrm{H} \mathrm{M}=$ modified Herbst, $\mathrm{TW}=$ Twin Block, MARS = mandibular advancement repositioning splint, $\mathrm{VB}=\mathrm{Van}$ Beek; RS = radiographic study, $\mathrm{CAT}=$ computed tomography, $\mathrm{CBCT}=$ cone beam computed tomography, $\mathrm{CTr}=$ cephalometric tracing, $\mathrm{ME}=$ manual examination, $\mathrm{MR}=$ magnetic resonance, $\mathrm{SPECT}=$ single proton emission computerized tomography, $\mathrm{WX}=\mathrm{wrist}$ $\mathrm{x}$-ray; $\mathrm{FT}=$ follow-up time, $\mathrm{T} 0=$ before treatment, $\mathrm{T} 1=$ at start of treatment, $\mathrm{T} 2=$ during treatment, $\mathrm{T} 3=$ immediately after treatment, $\mathrm{T} 4$ = later after treatment, $\mathrm{Tx}=$ treatment, $\mathrm{d}=$ days, $\mathrm{s}=$ weeks, $\mathrm{m}=$ months, $\mathrm{y}=$ years; $\mathrm{Q}=$ quality, $\mathrm{M}=$ medium, $\mathrm{H}=$ high. 


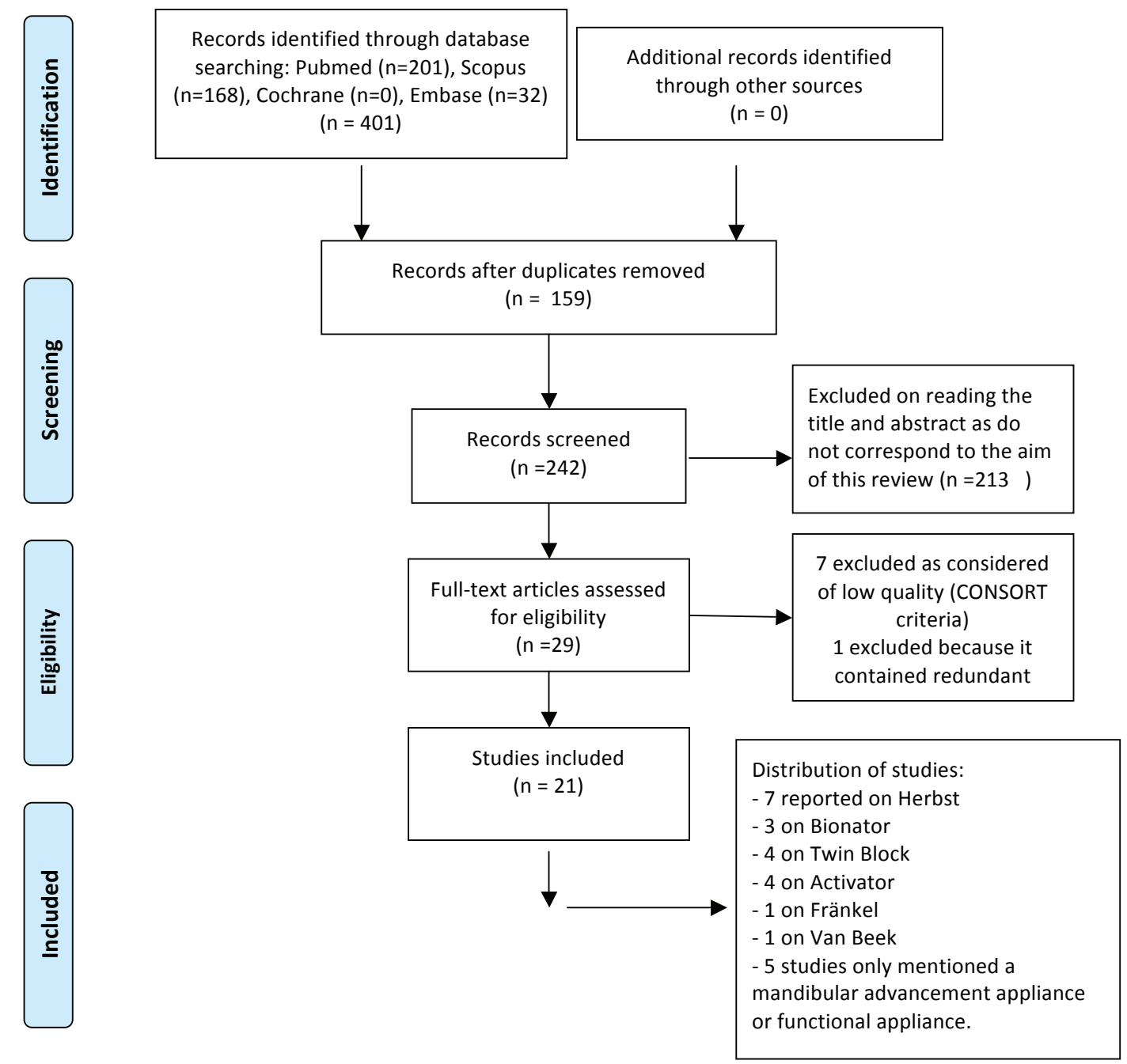

Fig. 1. Flow diagram.

Regarding the type of study reported in the 21 articles, 1 was a systematic review, 1 was a retrospective study and 19 were prospective studies. Of the prospective studies, 8 were controlled and 11 were not controlled (Table 1).

Concerning the state of the joint immediately prior to treatment, leaving aside the systematic review, only 8 of the studies explicitly mentioned its condition. Of these, 4 studied healthy joints and 4 studied joints with certain disorders (Table 2). The remaining 12 studies made no mention of joint status.

With regard to the type of appliance used, 7 studies used the Herbst appliance. Of these, 5 did not use control groups, 1 compared it with a functional advancement device and 1 with the Activator. The Bionator was studied in 3 articles, comparing it with the Twin Block in 2 cases. Two studies concerned the Twin Block alone, a further two the Activator alone and one the Fränkel, while another compared the Activator with the Van Beek. Three other articles did not name the type of appliance, mentioning only a functional or mandibular advancement appliance.

Only three studies specified the type of mandibular advancement (sequential or one-step).

In relation to the type of diagnostic study, 8 used magnetic resonance, 2 CBCT, 1 SPECT (single-proton emission computed tomography), 6 cephalometric tracing, 1 magnetic resonance together with manual examination, 1 magnetic resonance as well as cephalometric tracing and wrist radiographs, and 1 used magnetic resonance and teleradiography.

Regarding the quality of the articles, 19 were of moderate quality and one of high quality. The systematic review was considered of high quality. The main conclusions drawn by the authors of the studies included in the present review are shown in table 3 .

\section{Discussion}

- Changes in disk shape and position

According to Wadhawan et al. (15), the anterior repo- 
Table 2. Articles included, with information on pre-existing conditions.

\begin{tabular}{|c|c|c|}
\hline Author/year & $\begin{array}{c}\text { Prior TMJ status } \\
\text { (no. of joints affected) }\end{array}$ & Subsequent TMJ status \\
\hline Franco et al. 2002 (17) & $\begin{array}{l}\text { Control group } \\
\text { 7.1\% AMDD } \\
1.8 \% \text { DDWR } \\
5.3 \% \text { DDNR } \\
82.1 \% \text { DB } \\
10.7 \% \text { DNB } \\
\text { Treatment group } \\
\text { 89.3\% DB } \\
10.7 \% \text { DNB } \\
\end{array}$ & $\begin{array}{l}\text { T3: } \\
\text { Control group } \\
7.1 \% \text { AMDD } \\
\text { 10,7\% DNB } \\
\text { Treatment group } \\
100 \% \text { DNB }\end{array}$ \\
\hline Kinzinger et al. 2006 (28) & $\begin{array}{l}\text { Mouth closed and open } \\
7 \text { PADDWR } \\
3 \text { TADDWR } \\
1 \text { TADDNR }\end{array}$ & $\begin{array}{l}\text { T3: } \\
\text { Joints with no disorder: } \\
\text { No change } \\
\text { Joints with a disorder: } \\
6 \text { PADDWR } \\
1 \text { TADDWR } \\
1 \text { TADDNR }\end{array}$ \\
\hline Kinzinger et al. 2006 (8) & $\begin{array}{l}\text { Mouth closed and open } \\
24 \text { DDPR } \\
3 \text { TDDWR } \\
12 \text { PDDWR } \\
1 \text { TDDNR }\end{array}$ & $\begin{array}{l}\text { T3: } \\
30 \text { DDPR } \\
1 \text { TDDWR } \\
8 \text { PDDWR } \\
1 \text { TDDNR }\end{array}$ \\
\hline Aidar et al. 2010 (1) & T1: 11 ALDD & $\begin{array}{l}\text { T3: } 11 \text { LDD } \\
\text { T4: change from biconcave to } \\
\text { not biconcave in } 4 \text { joints }\end{array}$ \\
\hline
\end{tabular}

$\mathrm{AMDD}=$ antero-medial disk displacement, $\mathrm{ALDD}=$ antero-lateral disk displacement, $\mathrm{LDD}=$ lateral disk displacement, PADDWR $=$ partial anterior disk displacement with reduction, TADDWR $=$ total anterior disk displacement with reduction, TADDNR $=$ total anterior disk displacement with no reduction, TDDWR $=$ total disk displacement with reduction, PDDWR $=$ partial disk displacement with reduction, TDDNR $=$ total disk displacement with no reduction, DDWR = disk displacement with reduction, DDNR $=$ disk displacement with no reduction, DDPR $=$ disk displacement with partial reduction; $\mathrm{DB}=$ disk biconcave, $\mathrm{DNB}=$ disk not biconcave.

sitioning of the condyle in the glenoid fossa caused by functional appliances results in stretching of the retrodiscal tissue that could lead to changes in the shape of the disk or its posterior displacement, which agrees with the study by Chavan et al. (16). However, Aidar et al. (1) found no significant changes in disk position after treatment with the Herbst appliance. Franco et al. (17) observed no changes in comparison with the control group whether in healthy patients or in patients with antero-medial disk displacement, coinciding with the systematic review by Popowich et al. (18) and the study by Chintakanon et al. (19). Aidar et al. (9), in a previous study, made the same observation following 12 months' use of the Herbst appliance in adolescents whose disks were within the normal limits prior to treatment. In patients with prior disk displacement, these authors observed that it was not recaptured. However, Kinzinger et al. (20), using magnetic resonance, observed significant improvements in joints with an initial forward disk dislocation, agreeing with Kinzinger et al. (8), who also observed a lack of adverse effects in patients with a good initial condyle-disk relationship, as did Katsavrias et al. (6). Pancherz et al. (21) performed the same observation and indicated that the improvement in disk position depended on the extent of the initial displacement.

Concerning disk shape, Aidar et al. (9) reported a lack of adverse effects on articular disk morphology. Subsequently, the same authors (1) reached the same conclusion despite finding adverse effects in some patients at the end of the treatment, such as a change in disk shape from biconcave to not biconcave. Franco et al. (17), using magnetic resonance, observed that at the end of the treatment the number of biconcave discs had increased significantly in the patients treated with Fränkel appliances. As a result, they indicated that the use of this appliance at the beginning of the growth stage could help avoid future intra-TMJ problems.

- Changes in condyle size and position

In a case-control study of treatment with the Herbst appliance, Le Cornu et al. (3) observed forward adaptive displacement of the condyles followed by remodelling 
Table 3. Studies by observations.

\begin{tabular}{|c|c|c|}
\hline TMJ & Author/year & Q \\
\hline $\begin{array}{l}\text { After treatment with the Twin Block, the condyle occupied a more anterior position. There was no } \\
\text { evidence that the Twin Block had a positive or negative effect on disk position, or that the disk was } \\
\text { recaptured after the treatment. }\end{array}$ & $\begin{array}{l}\text { Chintakanon } \\
\text { et al. } 2000(19)\end{array}$ & M \\
\hline $\begin{array}{l}\text { The functional appliances did not cause temporomandibular disorder. The condyles were displaced } \\
\text { forwards. Although changes in disk position took place, the differences were not statistically significant. }\end{array}$ & $\begin{array}{l}\text { Arat et al. } 2001 \\
\quad(25)\end{array}$ & M \\
\hline $\begin{array}{l}\text { No significant changes were found following treatment (Bionator). The TMJ and condyle-disk } \\
\text { relationship retained their normal physiological status after treatment. }\end{array}$ & $\begin{array}{l}\text { Watted et al. } \\
2001(27)\end{array}$ & M \\
\hline $\begin{array}{l}\text { Favourable changes in the TMJ were observed in the sagittal plane, but were faster and better oriented } \\
\text { for correcting the sagittal problem in the Herbst group than in the Activator group. }\end{array}$ & $\begin{array}{l}\text { Baltromejus } \\
\text { et al. } 2002(5)\end{array}$ & M \\
\hline $\begin{array}{l}\text { There was no change in the position of the disk, but its shape improved (nearer to its normal biconcave } \\
\text { form). The Fränkel appliance can help to avoid future TMJ problems. }\end{array}$ & $\begin{array}{l}\text { Franco et al. } \\
2002(17)\end{array}$ & M \\
\hline Condylar growth was observed after using the functional appliance. & $\begin{array}{l}\text { Güner et al. } \\
2003(2)\end{array}$ & M \\
\hline $\begin{array}{l}\text { Changes in the angle and height of the articular eminence were observed, but were not statistically } \\
\text { significant. }\end{array}$ & $\begin{array}{l}\text { Katsavrias et al. } \\
\quad 2003(6)\end{array}$ & M \\
\hline $\begin{array}{l}\text { The amount and direction of growth in parts of the TMJ such as the glenoid fossa and condyles were } \\
\text { favourably affected, temporarily, in an anterior direction (Herbst). }\end{array}$ & $\begin{array}{l}\text { Pancherz et al. } \\
2003(21)\end{array}$ & M \\
\hline $\begin{array}{l}\text { The changes in the condyle and glenoid fossa were minor and not clinically relevant. The nature of the } \\
\text { remodelling of condyle and fossa was not established. }\end{array}$ & $\begin{array}{l}\text { Popovich et al. } \\
2003(18)\end{array}$ & $\mathrm{H}$ \\
\hline $\begin{array}{l}\text { Antero-inferior displacement of the glenoid fossa and postero-superior condylar growth were observed. } \\
\text { The latter was greater in hyperdivergent patients (Herbst). }\end{array}$ & $\begin{array}{l}\text { Pancherz et al. } \\
2004(22)\end{array}$ & M \\
\hline $\begin{array}{l}\text { No adverse effects were encountered in patients with no pre-existing disorder, and in patients with } \\
\text { disorders the disk position improved. }\end{array}$ & $\begin{array}{l}\text { Kinzinger et al. } \\
2006(28)\end{array}$ & M \\
\hline $\begin{array}{l}\text { No change in the condyle-fossa relationship were observed following treatment, and the TMJ remained } \\
\text { in a healthy state. }\end{array}$ & $\begin{array}{l}\text { Kinzinger et al. } \\
2006(7)\end{array}$ & M \\
\hline $\begin{array}{l}\text { The treatment has no adverse effects on patients without pre-existing disorders, and in patients with } \\
\text { partial or total disk displacement prior to treatment, an improvement in disk position may take place. }\end{array}$ & $\begin{array}{l}\text { Kinzinger et al. } \\
2006(8)\end{array}$ & M \\
\hline The Van Beek activator contributes to changes in the direction of condylar, maxillary and chin growth. & $\begin{array}{l}\text { Ruf et al. } 2007 \\
\quad(26)\end{array}$ & M \\
\hline Significant improvements in joints that presented forward disk dislocation. & $\begin{array}{l}\text { Kinzinger et al. } \\
2007(20)\end{array}$ & M \\
\hline $\begin{array}{l}\text { The condyle was shifted in a postero-superior direction in the group treated with the Herbst appliance. } \\
\text { There were no adverse changes. }\end{array}$ & $\begin{array}{l}\text { Serbesis- } \\
\text { Tsarudis et al. } \\
2008(4)\end{array}$ & $\mathrm{H}$ \\
\hline $\begin{array}{l}\text { The changes that took place returned to their initial state when the treatment ended, although the } \\
\text { condyle and glenoid fossa were remodelled in a more forward position. }\end{array}$ & $\begin{array}{l}\text { Wadhawan } \\
\text { et al. } 2008(15)\end{array}$ & $\mathrm{M}$ \\
\hline $\begin{array}{l}\text { In patients without a pre-existing disorder, no adverse changes took place. There were no changes in } \\
\text { disk position or shape following treatment. However, adverse effects in disk shape (from biconcave to } \\
\text { not biconcave) were observed in some patients. }\end{array}$ & $\begin{array}{l}\text { Aidar et al. } \\
2010(1)\end{array}$ & $\mathrm{M}$ \\
\hline $\begin{array}{l}\text { More anterior condyle position with adaptation of the glenoid fossa morphology and restricted maxillary } \\
\text { growth (Herbst). }\end{array}$ & $\begin{array}{l}\text { Le Cornu et al. } \\
2013(3)\end{array}$ & $\mathrm{M}$ \\
\hline $\begin{array}{l}\text { The condyles moved forward during the treatment and returned to their initial position when it ended, } \\
\text { although somewhat anterior to their pre-treatment location, while the disks presented a more posterior } \\
\text { repositioning. }\end{array}$ & $\begin{array}{l}\text { Chavan et al. } \\
2014(16)\end{array}$ & $\mathrm{M}$ \\
\hline $\begin{array}{l}\text { Increased condyle volume, mandibular length and inter-condyle distance were observed, but no adverse } \\
\text { effects. }\end{array}$ & $\begin{array}{l}\text { Yildirim et al. } \\
2014(23)\end{array}$ & $\mathrm{M}$ \\
\hline
\end{tabular}

$\mathrm{Q}=$ quality, $\mathrm{M}=$ medium, $\mathrm{H}=$ high.

of the glenoid fossa, compared with a control group that was only treated with fixed devices and class II elastic bands. These findings agree with those of Chintakanon et al. (19) and Chavan et al. (16). The latter conducted a controlled study using magnetic resonance and observed a more forward condyle position, although they recommended long-term follow-up to investigate the stability of their findings. In the same way, Pancherz et al. (22) observed that changes in condyle growth were greater in men than in women and highlighted that treatment with the Herbst appliance temporarily stimulated condyle growth. A year later, in a new study of 118 patients classified according to their growth pattern, Pancherz et al. (22) concluded that condyle growth took place and was more posterior in hyperdivergent than in hypodivergent subjects.

In contrast to the above observations, Kinzinger et al. (20) found no significant differences in the glenoid 
fossa-condyle relationship before and after treatment. Wadhawan et al. (15), using magnetic resonance, observed that the condyle and disk were displaced during treatment but returned to their initial position when the treatment ended. The systematic review by Popowich et al. (18) also concluded that the changes in condyle position were not clinically significant.

- Changes in the glenoid fossa

Pancherz et al. (21) observed antero-inferior displacement of the glenoid fossa as a reaction to the Herbst treatment. These authors asserted that the Herbst had an effect on the physiological growth of the fossa, temporarily displacing it forwards. However, the review by Popowich et al. (18) concluded that remodelling of the glenoid fossa had not been established, which agrees with the findings of Chintakanon et al. (19). Focusing on patients with different growth patterns, Pancherz et al. (22) concluded that there were no significant changes in the glenoid fossa between hyper- and hypodivergent subjects.

- Changes in the articular eminence and other changes

Reports on adaptations of the articular eminence caused by functional appliances are scarce. Katsavrias et al. (6) highlighted that the height of the articular eminence was not affected and that its angle suffered minor changes, but that these were insignificant.

With regard to other changes that may take place, according to the study by Le Cornu et al. (3) the Herbst appliance wearers exhibited restricted maxillary growth compared to the control group. Also, no great differences were found in the mandibular body and the growth of the ramus, in condyle flexibility or in changes in gonial angle. In contrast, Yildirim et al. (23) observed that treatment with the Twin Block increased the volume of the condyle, the length of the mandible and the intercondyle distance due to stimulation of condyle growth upwards and backwards.

- Limitations of this review

The scientific evidence collected on changes in the TMJ following the use of functional appliances was not abundant despite the thorough systematic search for articles that met the strict inclusion criteria and presented medium to high quality according to the CONSORT criteria.

TMJ status is a particularly important subject, yet this review has shown a lack of randomized controlled trials with long-term follow-up using diagnostic tests such as magnetic resonance and computed tomography to establish the effects of the functional appliance in a reliable way.

The articles included in the review show a lack of methodological homogeneity. For instance, Aidar et al. (9), Kinzinger et al. (20) and Wadhawan et al. (15) used magnetic resonance as a diagnostic method, while others such as Le Cornu et al. (3) and Arici et al.
(24) used CBCT. Yet others, like Baltromejus et al. (5) and Güner et al. (2), used cephalometric tracing. Many others, such as Arat et al. (25), preferred to use several methods to increase the accuracy of the results.

They also employed different appliances: while the great majority used the Herbst, others studied removable appliances such as Twin Block, Bionator $(15,16)$, Fränkel (17) or Activator (25). Only one of the studies (5) compared fixed and removable appliances, namely Activator and Herbst, concluding that the Herbst appliance corrected the sagittal problems in less time than the Activator.

Additionally, the sample size was small in most of these studies: Le Cornu et al. (3) studied 14 patients, Ruf et al. (26) 40 patients and Katsavrias et al. (6) 35 patients. Watted et al. (27) and Kinzinger et al. (28) studied 15 patients. The study with the largest sample size was Baltromejus et al. (5), with 138 cases.

\section{Conclusions}

- Following this review, it may be concluded that observations after treatment with functional appliances for mandibular advancement have found the condyle in a more advanced position, condyle remodelling and adaptation of the morphology of the glenoid fossa.

- No significant adverse events concerning the temporomandibular joint have been found in healthy patients, and this treatment could improve joints that initially presented forward disk dislocation.

\section{References}

1. Aidar LA, Dominguez GC, Yamashita HK, Abrahão M. Changes in temporomandibular joint disc position and form following Herbst and fixed orthodontic treatment. Angle Orthod. 2010;80:843-52.

2. Güner D, Öztürk Y, Sayman HB. Evaluation of the effects of functional orthopaedic treatment on temporomandibular joint with single- proton emission computerized tomography. Eur J Orthod. 2003;25:9-12.

3. Le Cornu M, Cevidanes LHS, Zhu H, Wu C, Larson B, Nguyenf T. Three-dimensional treatment outcomes in Class II patients treated with the Herbst appliance: A pilot study. Am J Orthod Dentofacial Orthop. 2013;144:818-30.

4. Serbesis-Tsarudis C, Pancherz H. "'Effective" TMJ and chin position changes in Class II treatment. Angle Orthod. 2008;78:813-8.

5. Baltromejus S, Ruf S, Pancherz H. Effective temporomandibular joint growth and chin position changes: Activator versus Herbst treatment. A cephalometric roentgenographic study. Eur J Orthod. 2002;24:627-37.

6. Katsavrias EG. The effect of mandibular protrusive (activator) appliances on articular eminence morphology. Angle Orthod. 2003;73:647-53.

7. Kinzinger G, Roth A, Gülden N, Bucker A, Diedrich P. Effects of orthodontic treatment with fixed functional orthopaedic appliances on the condyle-fossa relationship in the temporomandibular joint: a magnetic resonance imaging study (Part I). Dentomaxillofac Radiol. 2006;35:339-46.

8. Kinzinger GS, Roth A, Gülden N, Bücker A, Diedrich PR. Effects of orthodontic treatment with fixed functional orthopaedic appliances on the disc-condyle relationship in the temporomandibular joint: a magnetic resonance imaging study (Part II). Dentomaxillofac Radiol. 2006;35:347-56. 
9. Aidar LAA, Dominguez GC, Abrahao M, Yamashita HK, Vigorito JW. Effects of Herbst appliance treatment on temporomandibular joint disc position and morphology: A prospective magnetic resonance imaging study. Am J Orthod Dentofacial Orthop. 2009;136:412-24. 10. Liberati A, Altman DG, Tetzlaff J, Mulrow C, Gøtzsche PC, Ioannidis JP, et al. The PRISMA statement for reporting systematic reviews and meta-analyses of studies that evaluate health care interventions: explanation and elaboration. PLoS Med. 2009;6:e1000100. 11. Schulz KF, Altman DG, Moher D, Consort Group. Consort 2010 Statement: updated guidelines for reporting parallel group randomised trials. BMC Med. 2010;8:18

12. Mattos CT, Vilani GNL, Sant'Anna EF, Ruellas ACO, Maia LC. Effects of orthognathic surgery on oropharyngeal airway: a metaanalysis. Int J Oral Maxillofac Surg. 2011;40:1347-56.

13. Fernández-Ferrer L, Montiel-Company JM, Pinho T, AlmerichSilla JM, Bellot-Arcís C. Effects of mandibular setback surgery on upper airway dimensions and their influence on obstructive sleep apnoea - a systematic review. J Craniomaxillofac Surg. 2015;43:24853.

14. Serra-Torres S, Bellot-Arcís C, Montiel-Company JM, MarcoAlgarra J, Almerich-Silla JM. Effectiveness of mandibular advancement appliances in treating obstructive sleep apnea syndrome: A systematic review. Laryngoscope. 2016;126:507-14.

15. Wadhawan N, Kumar S, Kharbanda OP, Duggal R, Sharma R. Temporomandibular joint adaptations following two-phase therapy: an MRI study. Orthod Craniofac Res. 2008;11:235-50.

16. Chavan S, Bhad W, Doshi U. Comparison of temporomandibular joint changes in Twin Block and Bionator appliance therapy: a magnetic resonance imaging study. Prog Orthod. 2014;15:57.

17. Franco A, Yamashita H, Lederman H, Cevidanes LHS, Proffit W, Vigorito JW. Fränkel appliance therapy and the temporomandibular disc: A prospective magnetic resonance imaging study. Am J Orthod Dentofacial Orthop. 2002;121:447-57.

18. Popowich KDMD, Nebbe B. Effect of Herbst treatment on temporomandibular joint morphology: A systematic literature review. Am J Orthod Dentofacial Orthop. 2003;123:388-94.

19. Chintakanon K, Sampson W, Wilkinson T, Townsend T. A prospective study of Twin-block appliance therapy assessed by magnetic resonance imaging. Am J Orthod Dentofacial Orthop. 2000;118:494504.

20. Kinzinger G, Kober C, Diedrich P. Topography and Morphology of the Mandibular Condyle during Fixed Functional Orthopedic Treatment -a Magnetic Resonance Imaging Study. J Orofac Orthop. 2007;68:124-47.

21. Pancherz H, Fischer S. Amount and Direction of Temporomandibular Joint Growth Changes in Herbst Treatment: A Cephalometric Long-Term Investigation. Angle Orthod. 2003;73:493-501.

22. Pancherz H, Michailidou C. Temporomandibular joint growth changes in hyperdivergent and hypodivergent Herbst subjects. A long-term roentgenographic cephalometric study. Am J Orthod Dentofacial Orthop. 2004;126:153-61.

23. Yildirim E, Karacay S, Erkan M. Condylar response to functional therapy with Twin-Block as shown by cone-beam computed tomography. Angle Orthod. 2014;84:1018-25.

24. Arici S, Akan H, Yakubov K, Arici N. Effects of fixed functional appliance treatment on the temporomandibular joint. Am J Orthod Dentofacial Orthop. 2008;133:809-14.

25. Arat Z, Gökalp H, Erdem D, Erden I. Changes in the TMJ disccondyle-fossa relationship following functional treatment of skeletal Class II Division 1 malocclusion: A magnetic resonance imaging study. Am J Orthod Dentofacial Orthop. 2001;119:316-9.

26. Ruf S, Bendeus M, Pancherz H, Hägg U. Dentoskeletal Effects and "Effective" Temporomandibular Joint, Maxilla and Chin Changes in Good and Bad Responders to van Beek Activator Treatment. Angle Orthod. 2007;77:64-72.

27. Watted N, Witt E, Kenn W. The temporomandibular joint and the disc-condyle relationship after functional orthopaedic treatment: a magnetic resonance imaging study. Eur J Orthod. 2001;23:683-93.
28. Kinzinger G, Gülden N, Roth A, Diedrich P. Disc-condyle Relationships during Class II Treatment with the Functional Mandibular Advancer (FMA). J Orofac Orthop. 2006;67:356-75.

\section{Acknowledgements}

The authors have no funding, financial relationships, or conflicts of interest to disclose.

The manuscript was translated into English by Mary Georgina Hardinge.

\section{Conflict of Interest}

The authors have declared that no conflict of interest exist. 